\title{
DYSCERNE: a European Network of Centres of Expertise for Dysmorphology
}

\author{
Krystyna Chrzanowska ${ }^{1 *}$, Jill Clayton-Smith ${ }^{2}$, Ruth Day ${ }^{2}$, Pamela Griffiths ${ }^{2}$ \\ From 5th European Conference on Rare Diseases (ECRD 2010) \\ Krakow, Poland. 13-15 May 2010
}

There are over 2,500 identifiable dysmorphic conditions, which individually are rare but together form a significant proportion of referrals to a genetic service. The rarity of these diseases means that even in Centres of Expertise established in many EU countries, experience can be limited, resulting in delay or uncertainty of diagnosis.

To improve diagnosis of dysmorphic syndromes across the EU, a formal European Network for Dysmorphology was created within the EU-funded DYSCERNE project (2007-2010) coordinated by the UK (University of Manchester). It links a total of 85 centres, including 32 centres of expertise with the remaining centres acting as case submission nodes for a web-based electronic Dysmorphology Diagnostic System (DDS). Making a correct diagnosis is essential for patient management and for providing accurate information and counselling. The DDS allows rapid access for clinicians from across Europe to expert opinions increasing accuracy of diagnosis. It will also facilitate definition and classification of rare dysmorphic disorders and promote further research. Linked to DDS, educational tools in a modern, on-line format were created aimed to guide and educate clinicians throughout Europe on key aspects of clinical dysmorphology (http://www.dyscerne.org). One of the principal activities of the DYSCERNE network was developing best practice management guidelines which use a robust methodology. Management protocols for four selected conditions: Angelman, Noonan, Kabuki and Williams Syndromes will be available on the DYSCERNE website soon.

There is a need to continue activities initiated by DYSCERNE, in particular to sustain European networking, which helps to make a correct diagnosis and

\footnotetext{
*Correspondence: k.chrzanowska@czd.pl

'The Children's Memorial Heath Institute, Warsaw, Poland

Full list of author information is available at the end of the article
}

continue development of management guidelines for further rare diseases.

DYSCERNE is funded by the European Commission Public Health Executive Agency (DG Sanco) Project 2006122 - A European Network of Centres of Expertise for Dysmorphology, and is supported by the Manchester Academic Health Sciences Centre (MAHSC) and the NIHR Biomedical Research Centre.

\section{Acknowledgements}

The Dyscerne Network: K. Devriendt, H. Brunner, I. van den Burgt, B. Dallapiccola, M. Krajewska-Walasek, N. Philip, D. Donnai , K. Metcalfe, B. Kerr, S. Gardner, K. Strong.

\section{Author details}

${ }^{1}$ The Children's Memorial Heath Institute, Warsaw, Poland. ${ }^{2}$ University of Manchester, Manchester, UK.

Published: 19 October 2010

doi:10.1186/1750-1172-5-S1-014

Cite this article as: Chrzanowska et al:: DYSCERNE: a European Network of Centres of Expertise for Dysmorphology. Orphanet Journal of Rare Diseases 2010 5(Suppl 1):014.

\section{Submit your next manuscript to BioMed Central and take full advantage of: \\ - Convenient online submission \\ - Thorough peer review \\ - No space constraints or color figure charges \\ - Immediate publication on acceptance \\ - Inclusion in PubMed, CAS, Scopus and Google Scholar \\ - Research which is freely available for redistribution

